\title{
The Relationship between Smartphone Use and Oral Health in Adolescents
}

\author{
Eunsuk $\mathrm{Ahn}^{1}$ and Ji-Hyoung $\mathrm{Han}^{2, \dagger}$ \\ 'Department of Dental Hygiene, Daejeon Institute of Science and Technology, Daejeon 35408, \\ ${ }^{2}$ Department of Dental Hygiene, Suwon Science College, Hwaseong 18516, Korea
}

\begin{abstract}
Background: Smartphones are a modern necessity. While they are convenient to use, smartphones also have side effects such as addiction. This study assessed the relationship between smartphone use, a part of everyday life in modern society, and oral health.

Methods: An analysis was conducted using 2017 Korea Youth Risk Behavior Web-based Survey data. The propensity score estimation algorithm used logistic regression and 1:1 matching algorithm using nearest-neighbor matching. After matching, a total of 15,032 participants were classified into two groups containing 7,516 teenagers each who did and did not use smartphones, respectively.

Results: Comparison of oral health behaviors according to smartphone use revealed a statistically significant difference in the frequency of tooth brushing per day, use of oral hygiene products, intake of foods harmful to oral health, and experience of oral health education $(p<0.05)$. The factors affecting oral pain experience of adolescents were examined. Compared to male participants, female participants had an odds ratio of 1.627 for oral pain $(p<0.05)$. According to the household income level, compared to the group with higher income, the group with lower income showed higher oral pain experience $(p<0.05)$. Oral pain experience was 1.601 times more frequent among teenagers using smartphones $(p<0.05)$.

Conclusion: The results of this study indicated that use of smartphones by adolescents affected their oral health. These findings indicate the need for improved oral health management through the use of effective school oral health programs and individual counseling by oral health professionals, promotion of information dissemination through public media, and development of prevention strategies.
\end{abstract}

Key Words: Adolescent, Oral health, Smartphone

\section{Introduction}

In addition to Internet use, smartphones are now a necessity for modern life. Daily living activities start and end with the use of a smartphone. People use their smartphones for financial services and news, social media, messengers, movies, reading, watching television, and playing games. As such, smartphones have a net function that makes everyday life easier. However, while smartphones offer conveniences, they also have side effects such as addiction.
According to the Ministry of Science and ICT and the Korea Internet \& Security Agency, $89.5 \%$ of individuals over 3 years of age had smartphones in 2018, 19.1\% of whom are at risk of overdependency. In particular, $34.0 \%$ of middle school students and $28.3 \%$ of high school students were at risk for overdependence, the highest rates compared with other age groups. The use of messengers by content was the highest, followed by social networking service (SNS), news, movies, television, videos, and games ${ }^{11}$.

Adolescent overdependence on smartphones causes problems in communication with others due to neglect of 
external relationships and reduced ability to adapt to school life ${ }^{2,3)}$. In addition, overdependence has been reported to negatively affect not only family relationships, mental health, and sleep disturbances but also physical health and eating habits ${ }^{4,5)}$. Furthermore, smartphone use is associated with decreased physical activity and has been reported to affect obesity rates depending on smartphone usage time ${ }^{6,7)}$.

Adolescence is a period of rapid physical development as well as psychological and social growth. The health beliefs and behaviors formed in adolescence affect adulthood. Therefore, attention to adolescent health is important $^{8,9)}$. The general characteristics of the oral condition of adolescents frequently include increased snack intake, multiple dental caries, and progression from gingivitis to periodontal disease ${ }^{10)}$. Oral health care in adolescence is important because dental caries and periodontal disease, which are serious oral diseases, affect tooth loss in adulthood and old age. Korean adolescents may neglect oral health care because of stress and lack of time due to schoolwork. Especially in the modern society, the side effects of smartphones are additive; thus, increased attention is required.

Although studies have compared the relationship between smartphone use and oral health in adolescents, few have compared factors affecting oral health after adjusting for demographic factors. This study investigated the factors affecting the oral health of adolescents after propensity score matching for socio-demographic characteristics. The results of this study are intended to provide basic data for policies related to the use of smart devices in oral health promotion projects in adolescents.

\section{Materials and Methods}

\section{Subjects}

This study analyzed data from the 2017 Korea Youth Risk Behavior Web-based Survey. In general, selection bias may occur in observational studies when selecting target and comparative groups. Accurate inferences of causality are not possible or can also lead to errors that can underestimate or overestimate the results ${ }^{11,12)}$. Therefore, this study selected variables to control for confounding variables in the design stage, calculated the variables as covariates, and used propensity score matching to form similar experimental and control groups ${ }^{13)}$. The propensity score estimation algorithm used logistic regression and a 1:1 matching algorithm using nearest-neighbor matching. The covariates were sex, age, and economic status and the binary treatment indicators were based on smartphone use. The study population before matching was 61,861; after matching, 7,516 adolescents each were classified into smartphone and non-smartphone use groups, with a total of 15,032 participants.

\section{Variables used in the analysis}

The variables used in the analysis are shown in Table 1. The questions "Have you had a tooth sore in the last 12 months?" and "Have you had gum pain or bleeding in the last 12 months?" were used as oral pain variables. The covariates considered socio-demographic characteristics such as sex, age, and household income level. The independent variables included smartphone use and oral health behaviors including intake of soda drinks, sweet

Table 1. Definition of Variables

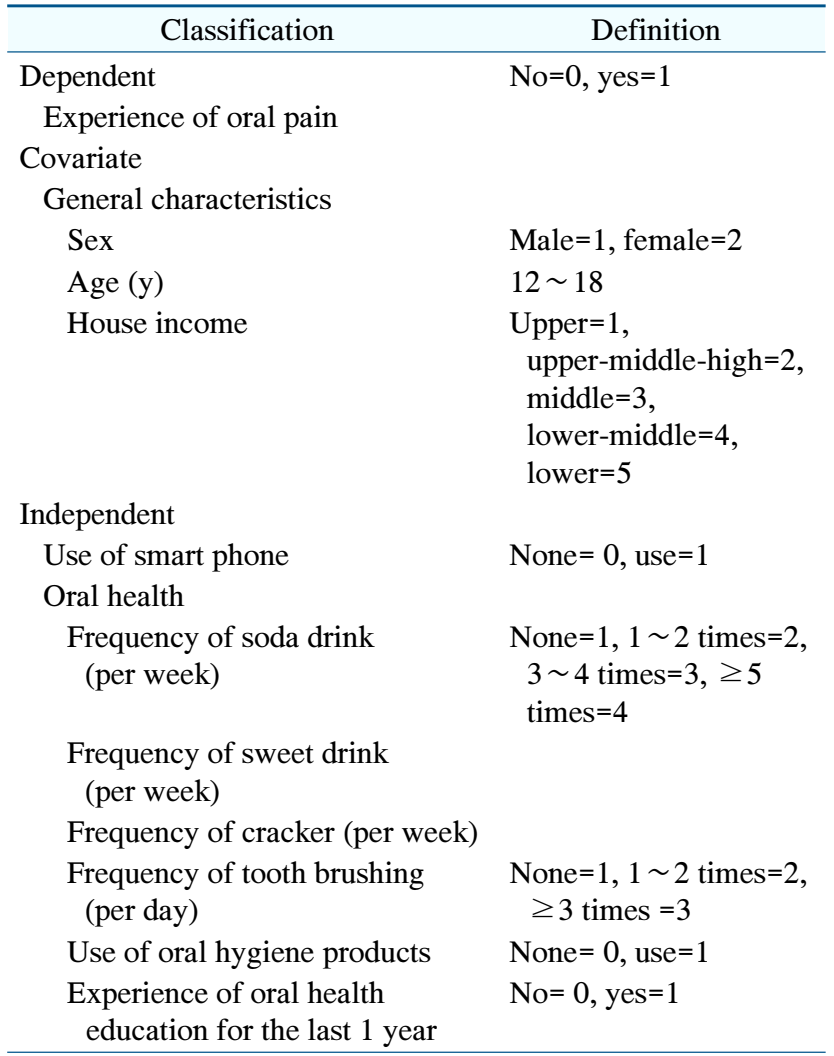


drinks, and cracker over the past week. The analysis also included the average frequency of tooth brushing per day, use of oral hygiene products, and oral health education experiences.

\section{Data analysis}

The general characteristics of the study subjects were confirmed through frequency analysis. Chi-square tests were performed to compare oral health behaviors and oral pain experiences according to smartphone use. Finally, logistic regression analysis was performed to identify factors affecting oral pain experience. All analyses were performed using STATA version 14.0 (Stata Corp., College Station, TX, USA) with a significance level of $\mathrm{p}=0.05$.

\section{Results}

\section{General characteristics}

The general characteristics of the subjects are shown in Table 2. The distribution of the characteristics between the two groups before and after propensity score matching was compared to make the distribution similar between the groups according to smartphone use, the characteristics between the group using smartphone and the group without the smartphone were used as covariate variables. It was observed that the differences in the characteristics of the individuals in the group decreased.

\section{Comparison of oral health behavior according to smartphone use}

A comparison of oral health behavior in adolescents according to smartphone use is shown in Table 3. The average frequency of tooth brushing per day, use of oral hygiene products, intake of foods harmful to oral health, and experience of oral health education differed significantly between user groups $(p<0.05)$. The daily average frequency of tooth brushing showed a higher proportion of adolescents who brushed more than three times daily among those who did not use a smartphone (50.31\%) compared to those who used a smartphone (49.69\%). However, the use of axillary oral hygiene products was higher in smartphone used adolescents (52.47\%) than that in adolescents who did not use smartphones (47.53\%). Comparison of foods that are harmful to oral health showed that adolescents who did not use smartphones do

Table 2. Sample Characteristics

\begin{tabular}{|c|c|c|c|c|}
\hline \multirow{2}{*}{ Characteristic } & \multicolumn{2}{|c|}{ Use of smartphone before PSM $(n=61,861)$} & \multicolumn{2}{|c|}{ Use of smartphone after PSM $(n=15,032)$} \\
\hline & None & Use & None & Use \\
\hline \multicolumn{5}{|l|}{ Sex } \\
\hline Male & $26,777(49.27)$ & $4,576(60.88)$ & $4,576(60.88)$ & $4,576(60.88)$ \\
\hline Female & $27,568(50.73)$ & $2,940(39.12)$ & $2,940(39.12)$ & $2,940(39.12)$ \\
\hline \multicolumn{5}{|l|}{ Age (y) } \\
\hline 12 & $4,353(8.01)$ & $634(8.44)$ & $634(8.44)$ & $634(8.44)$ \\
\hline 13 & $9,028(16.61)$ & $1,252(16.66)$ & $1,252(16.66)$ & $1,252(16.66)$ \\
\hline 14 & $8,971(16.51)$ & $1,315(17.50)$ & $1,315(17.50)$ & $1,315(17.50)$ \\
\hline 15 & $9,097(16.74)$ & $1,238(16.47)$ & $1,238(16.47)$ & $1,238(16.47)$ \\
\hline 16 & $9,478(17.44)$ & $1,229(16.35)$ & $1,229(16.35)$ & $1,229(16.35)$ \\
\hline 17 & $9,583(17.63)$ & $1,291(17.18)$ & $1,291(17.18)$ & $1,291(17.18)$ \\
\hline 18 & $3,835(7.06)$ & $557(7.41)$ & $557(7.41)$ & $557(7.41)$ \\
\hline \multicolumn{5}{|l|}{ House income } \\
\hline Upper & 5,428 (9.99) & 1,137 (15.13) & $1,137(15.13)$ & $1,137(15.13)$ \\
\hline Upper-middle & $15,976(29.40)$ & $2,063(27.45)$ & $2,063(27.45)$ & $2,063(27.45)$ \\
\hline Middle & $25,238(46.44)$ & $3,256(43.32)$ & $3,256(43.32)$ & $3,256(43.32)$ \\
\hline Lower-Middle & $6,422(11.82)$ & $830(11.04)$ & $830(11.04)$ & 830 (11.04) \\
\hline Lower & $1,281(2.36)$ & $230(3.06)$ & $230(3.06)$ & $230(3.06)$ \\
\hline
\end{tabular}

Values are presented as $\mathrm{n}(\%)$.

PSM: propensity score matching. 
Table 3. Oral Health Behavior according to Using Smart Phone

\begin{tabular}{|c|c|c|c|c|}
\hline \multirow[b]{2}{*}{ Variable } & \multicolumn{2}{|c|}{ Use of smartphone $(n=7,516)$} & \multirow[b]{2}{*}{$\chi^{2}$} & \multirow[b]{2}{*}{ p-value } \\
\hline & None & Use & & \\
\hline \multicolumn{5}{|l|}{ Frequency of tooth brushing } \\
\hline None & $128(62.44)$ & $77(37.56)$ & 28.92 & $<0.001$ \\
\hline$\leq 2$ times & $521(44.23)$ & $657(55.77)$ & & \\
\hline$\geq 3$ times & $6,867(50.31)$ & $6,782(49.69)$ & & \\
\hline \multicolumn{5}{|l|}{ Use of oral hygiene products } \\
\hline None & $6,466(50.43)$ & $6,357(49.57)$ & 6.31 & 0.01 \\
\hline Use & $1,050(47.53)$ & $1,159(52.47)$ & & \\
\hline \multicolumn{5}{|c|}{ Frequency of soda drink (per week) } \\
\hline None & $1,742(53.88)$ & $1,491(46.12)$ & 35.12 & $<0.001$ \\
\hline $1 \sim 2$ times & $3,295(49.33)$ & $3,385(50.67)$ & & \\
\hline $3 \sim 4$ times & $1,531(46.82)$ & $1,739(53.18)$ & & \\
\hline$\geq 5$ times & $948(51.27)$ & $901(48.73)$ & & \\
\hline \multicolumn{5}{|c|}{ Frequency of sweet drink (per week) } \\
\hline None & $1,295(60.26)$ & $854(39.74)$ & 157.90 & $<0.001$ \\
\hline $1 \sim 2$ times & $3,110(51.67)$ & $2,909(48.33)$ & & \\
\hline $3 \sim 4$ times & $1,884(45.72)$ & $2,237(54.28)$ & & \\
\hline$\geq 5$ times & $1,227(44.73)$ & $1,516(55.27)$ & & \\
\hline \multicolumn{5}{|c|}{ Frequency of cracker (per week) } \\
\hline None & $1,500(53.80)$ & $1,288(46.20)$ & 29.23 & $<0.001$ \\
\hline $1 \sim 2$ times & $3,373(50.39)$ & $3,321(49.61)$ & & \\
\hline $3 \sim 4$ times & $1,896(47.78)$ & $2,072(52.22)$ & & \\
\hline$\geq 5$ times & $747(47.22)$ & $835(52.78)$ & & \\
\hline \multicolumn{5}{|l|}{ Experience of oral education } \\
\hline No & $4,615(55.54)$ & $3,695(44.46)$ & 227.77 & $<0.001$ \\
\hline Yes & $2,901(43.16)$ & $3,821(56.84)$ & & \\
\hline
\end{tabular}

p-value of Chi-squared test.

not consume these foods than once weekly compared to adolescents who used smartphones. A difference was also observed in the types of food ingested. Comparison of consumption of foods harmful to oral health more than five times per week showed higher ingestion of sweet drinks (55.27\%) and sweets (52.78\%) among smartphone users. Similarly, more adolescent smartphone users had experience with oral health education (56.84\%).

\section{Factors influencing the oral pain experience of adolescents}

Table 4 shows the factors influencing the oral pain experience of adolescents. Compared to male participants, female participants had an odds ratio of 1.627 for oral pain $(p<0.05)$. According to household income level, participants with lower income had experienced oral pain more often than had those with higher income. In particular, the group with lower income had an odds ratio twice that in the higher income group. Increased intake of foods that are harmful to oral health is associated with higher occurrence of oral pain $(p<0.05)$. Adolescents who brushed their teeth three or more times per day tended to experience less oral pain than did those who did not brush their teeth $(\mathrm{p}<$ 0.05). Analysis of the experience of oral pain according to smartphone use showed more frequent pain among those using smartphones, with an odds ratio of $1.601(\mathrm{p}<0.05)$.

\section{Discussion}

Smartphones provide convenience and pleasure to our lives. However, excessive smartphone use can lead to addiction and side effects such as poor academic performance, cognitive function, and emotional control, as well as interpersonal difficulties. In particular, adolescents 
Table 4. Factors Affecting Experience of Oral Pain

\begin{tabular}{|c|c|c|c|c|}
\hline Variable & OR $(95 \% \mathrm{CI})$ & SE & $\mathrm{z}$ & p-value \\
\hline \multicolumn{5}{|l|}{ Sex } \\
\hline Male & (Ref) & & & \\
\hline Female & $1.627(1.517 \sim 1.745)$ & 0.058 & 13.61 & $<0.001$ \\
\hline \multicolumn{5}{|l|}{ School } \\
\hline Middle school & (Ref) & & & \\
\hline High school & $1.119(1.097 \sim 1.142)$ & 0.012 & 10.90 & $<0.001$ \\
\hline \multicolumn{5}{|l|}{ House income } \\
\hline Upper & (Ref) & & & \\
\hline Upper-middle & $1.497(1.342 \sim 1.669)$ & 0.083 & 7.26 & $<0.001$ \\
\hline Middle & $1.475(1.330 \sim 1.634)$ & 0.077 & 7.40 & $<0.001$ \\
\hline Lower-Middle & $1.979(1.730 \sim 2.263)$ & 0.135 & 9.97 & $<0.001$ \\
\hline Lower & $2.001(1.623 \sim 2.466)$ & 0.213 & 6.50 & $<0.001$ \\
\hline \multicolumn{5}{|c|}{ Soda drink (per week) } \\
\hline None & (Ref) & & & \\
\hline $1 \sim 2$ times & $1.018(0.930 \sim 1.114)$ & 0.047 & 0.38 & 0.703 \\
\hline $3 \sim 4$ times & $1.107(0.993 \sim 1.234)$ & 0.061 & 1.83 & 0.067 \\
\hline$\geq 5$ times & $1.121(0.984 \sim 1.278)$ & 0.075 & 1.72 & 0.085 \\
\hline \multicolumn{5}{|c|}{ Sweet drink (per week) } \\
\hline None & (Ref) & & & \\
\hline $1 \sim 2$ times & $1.282(1.151 \sim 1.427)$ & 0.070 & 4.53 & $<0.001$ \\
\hline $3 \sim 4$ times & $1.439(1.280 \sim 1.618)$ & 0.086 & 6.10 & $<0.001$ \\
\hline$\geq 5$ times & $1.59(1.396 \sim 1.811)$ & 0.106 & 6.98 & $<0.001$ \\
\hline \multicolumn{5}{|l|}{ Cracker (per week) } \\
\hline None & (Ref) & & & \\
\hline $1 \sim 2$ times & $1.085(0.987 \sim 1.191)$ & 0.052 & 1.70 & 0.09 \\
\hline $3 \sim 4$ times & $1.189(1.071 \sim 1.319)$ & 0.063 & 3.26 & 0.001 \\
\hline$\geq 5$ times & $1.383(1.211 \sim 1.579)$ & 0.094 & 4.78 & $<0.001$ \\
\hline \multicolumn{5}{|c|}{ Frequency of tooth brushing } \\
\hline None & (Ref) & & & \\
\hline$\leq 2$ times & $0.978(0.719 \sim 1.329)$ & 0.153 & -0.14 & 0.886 \\
\hline$\geq 3$ times & $0.683(0.513 \sim 0.909)$ & 0.100 & -2.62 & 0.009 \\
\hline \multicolumn{5}{|c|}{ Use of oral hygiene products } \\
\hline None & (Ref) & & & \\
\hline Use & $0.939(0.854 \sim 1.031)$ & 0.045 & -1.32 & 0.188 \\
\hline \multicolumn{5}{|c|}{ Experience of oral education } \\
\hline No & (Ref) & & & \\
\hline Yes & $1.178(1.092 \sim 1.270)$ & 0.045 & 4.25 & $<0.001$ \\
\hline \multicolumn{5}{|l|}{ Use of smart phone } \\
\hline None & (Ref) & & & \\
\hline Use & $1.601(1.497 \sim 1.711)$ & 0.054 & 13.83 & $<0.001$ \\
\hline Constant & $0.123(0.084 \sim 0.182)$ & 0.024 & -10.64 & $<0.001$ \\
\hline
\end{tabular}

p-value of logistic regression.

OR: odds ratio, CI: confidence interval, SE: standard error, Ref: reference.

are highly addicted to the Internet, smartphones, and games ${ }^{14)}$. This study investigated the relationship between smartphone use and oral health in adolescents.

Comparison of oral health behaviors according to smartphone use showed that many adolescents without smartphones brushed their teeth more than three times a day. Comparison of the consumption of foods that are harmful to oral health revealed that adolescents using smartphones consumed sweets drinks and sweets more than five times a week. Lim and $\mathrm{Kim}^{4}$ ) reported a high 
intake ratio of bread or sweets in snacks among smartphone users and Kim and $\mathrm{Kim}^{15)}$ reported decreased the size of each meals, delayed meal speed, and increased number of snacks with smartphone use. In addition, Namkoong and $\mathrm{Ma}^{16)}$ reported negative experiences with smartphone use, included changed interests in oral health. Thus, poor behavior and lack of interest caused by smartphone use affect oral health. However, smartphone users had more experience in terms of oral health education. Nevertheless, the poor oral health behaviors in this population suggest the need to develop and utilize smartphone-based oral health education materials.

Factors affecting oral pain experiences were more often observed in female than in male and participants with lower household incomes experienced more pain. In particular, the group with lower income experienced twice as much pain as did the group with higher income. Besides smartphone use, socioeconomic factors also affect oral health. Therefore, the oral health of vulnerable-class teenagers addicted to smartphones will be more adversely affected. Identification of various ways to manage oral health care is required for this population. There is a need for oral health projects to improve social environment interventions and oral health equity. In particular, revitalization of school oral health programs is required ${ }^{17)}$.

Oral pain was 1.6 times more frequently reported among teenagers using smartphones. Do ${ }^{18)}$ reported an association between longer Internet usage time and increased risk of oral symptom experience, with a 1.17- and 1.25-fold increase in the risk of oral symptoms for 5 to 6 and more than 7 hours of use, respectively, compared to within 1 hour of use. Smartphone use has been proven to be a factor affecting oral pain and symptom experience. In modern society, it is not desirable to suppress unconditional use to eliminate the side effects of smartphone use in adolescents. Kim et al. ${ }^{3)}$ reported that adolescents complained more of the problems of overuse and restraint than did other age groups and recognized their problems. However, they were dissatisfied with external controls such as parent or teacher arrangements. Therefore, decreased oral health care caused by smartphone dependence may be appropriately controlled by individual consultations with oral health professionals. In addition, public relations and content development for prevention and public awareness are needed for dissemination by parents, schools, and teachers ${ }^{2)}$.

This study has limitations inherent to cross-sectional studies in proving causal relationships. In addition, this study focused only on the use of smartphones; additional studies are needed to determine the effects of factors such as the purpose of use of smartphones and usage time on adolescents' oral health. Nevertheless, it is meaningful to study the relationship between smartphone use, which is becoming a problem in modern society, and adolescents during the important periods during which lifelong oral health habits are formed. Future studies should assess study oral health behaviors according to the purpose of smartphone use such as messenger, SNS, and games.

\section{Notes}

\section{Conflict of interest}

No potential conflict of interest relevant to this article was reported.

\section{Ethical approval}

This study was approved by the Institutional Review Board of Suwon Science College, which also approved the secondary data analysis (IRB2-7008167-AB-N-01-201805HR-001-01).

\section{Author contributions}

Conceptualization: Eunsuk Ahn, Ji-Hyoung. Data acquisition: Eunsuk Ahn. Formal analysis: Eunsuk Ahn. Funding: Eunsuk Ahn, Ji-Hyoung Han. Supervision: Eunsuk Ahn, Ji-Hyoung Han. Writing-original draft: Eunsuk Ahn, Ji-Hyoung Han. Writing-review \& editing: Eunsuk Ahn, Ji-Hyoung Han.

\section{ORCID}

Eunsuk Ahn, https://orcid.org/0000-0002-9404-4826

Ji-Hyoung Han, https://orcid.org/0000-0003-1613-2879

\section{References}

1. Ministry of Science and ICT and National Information 
Society Agency: 2018 the survey on smart phone overdepedndence. ICT and National Information Society Agency, Daegu, pp.33-39, 2018.

2. Ha TH, Beak HG: A study on relationships between youth smart phone addiction and mind health, and parameter effect of school life adaptation. J Korean Assoc Comput Educ 17: 147-159, 2014.

3. Kim NR, Yoo KU, Kim JH, Lee KH: The concept map on smartphone stress factors based on the life-stage (adolescent, undergraduate, and office worker). Korean J Health Psychol 22: 745-777, 2017.

4. Lim HS, Kim SK: Analysis of health habit and hair mineral nutrition status of media addicted adolescent. J Nutr Health 51: 295-306, 2018. https://doi.org/10.4163/jnh.2018.51.4.295

5. No UK: Meta-analysis about relationship between adolescents' smartphone addiction and mental health. J Res Educ 31: 141-168, 2018.

6. Jeong MK, Kim GM, Jung HH, Park SK: The association between smartphone dependence trends and body mass index $\&$ health fitness in adolescents. J Sport Leis Stud 78: 461-469, 2019.

7. Park MH, Song HY: Relationship among the Korean adolescents obesity, health behavior and smart phone usage. J Korean Public Health Nurs 33: 47-58, 2019. https://doi.org/10.5932/JKPHN.2019.33.1.47

8. Hancox RJ, Milne BJ, Poulton R: Association between child and adolescent television viewing and adult health: a longitudinal birth cohort study. Lancet 364: 257-262, 2004. https://doi.org/10.1016/S0140-6736(04)16675-0

9. Blum RW, Garell D, Hodgman CH, et al.: Transition from child-centered to adult health-care systems for adolescents with chronic conditions. A position paper of the Society for Adolescent Medicine. J Adolesc Health 14: 570-576, 1993. https://doi.org/10.1016/1054-139x(93)90143-d

10. Cockerham WC, Sharp K, Wilcox JA: Aging and perceived health status. J Gerontol 38: 349-355, 1983.

https://doi.org/10.1093/geronj/38.3.349

11. Jang MH, Park CG: Risk factors influencing probability and severity of elder abuse in community-dwelling older adults: applying zero-inflated negative binomial modeling of abuse count data. J Korean Acad Nurs 42: 819-832, 2012. https://doi.org/10.4040/jkan.2012.42.6.819

12. Caliendo M, Kopeinig S: Some practical guidance for the implementation of propensity score matching. J Econ Surv 22: 31-72, 2008.

https://doi.org/10.1111/j.1467-6419.2007.00527.x

13. Rosenbaum PR, Rubin DB: The central role of the propensity score in observational studies for causal effects. Biometrika 70: 41-55, 1983.

14. Cho HS: A study on the solution for the internet, smartphone, and internet game addiction of teenagers. Korean $\mathrm{J}$ Youth Stud 26: 291-310, 2019. https://doi.org/10.21509/KJYS.2019.10.26.10.291

15. Kim EJ, Kim SY: Correlation between smartphone addiction and eating behaviors of elementary school students in Ansan area. J Korean Soc Food Sci Nutr 44: 1007-1015, 2015. https://doi.org/10.3746/jkfn.2015.44.7.1007

16. Namkoong EJ, Ma DS: Correlation between oral health behaviors and problematic experiences associated with smartphone use in adolescents. J Korean Acad Oral Health 43: 157-162, 2019.

17. Heo $\mathrm{HH}$, Che $\mathrm{XH}$, Jeong WJ, Chung HJ: Evaluation of community interventions to reduce health inequity in socioeconomically vulnerable populations. Korean J Health Educ Promot 34: 1-13, 2017. https://doi.org/10.14367/kjhep.2017.34.2.1

18. Do KY: Impact of health risk factors on the oral health of Korean adolescents: Korea youth risk behavior web-based survey, 2013. J Dent Hyg Sci 16: 193-199, 2016. https://doi.org/10.17135/jdhs.2016.16.3.193 